\section{Las tensiones de la imagen de mujer en la moda Colombiana (1990-2000). Un análisis de la representación de la publicidad en la década de 1990}

Angela Liliana Dotor Robayo ${ }^{(1)}$

\begin{abstract}
Resumen: Este artículo hace parte de la investigación de la tesis doctoral en diseño: "El vestido y el conflicto en Colombia 1984 al 2000. El caso del jean colombiano". Se presenta aquí una reflexión sobre la imagen de mujer representada en revistas y diarios nacionales, argumentada en la revisión y posterior análisis tanto de fotografía como de publicidad de moda de la década de 1990 en Colombia, y se analiza el discurso visual asociado a la mujer representada. Para el análisis fue necesario profundizar en la relación de la imagen con los contextos, en la contrastación con el periodo histórico anterior y profundizar en la hexis corporal de la indumentaria para entender sus continuidades y transformaciones, lo que permitió encontrar una relación directa con la esfera cultural del mundo narco, la cual no solo produjo violencia e ilegalidad en Colombia, sino también se insertó en la cultura a través de textos, objetos, modos y expresiones objetivas que produjeron imaginarios de poder que influenciaron y transformaron una parte de la sociedad colombiana hacia una sociedad narcotizada y productora de una narco-estética.
\end{abstract}

Palabras clave: semiosfera - mujer - estética narco - vestido - Colombia.

[Resúmenes en inglés y portugués en las páginas 67-68]

(1) Profesora asociada II, programa de Diseño y Gestión de la Moda, Universidad de Bogotá Jorge Tadeo Lozano, angelal.dotorr@utadeo.edu.co, langeldr@yahoo.com.br; Profesional en Diseño de Modas y Textiles, con especialización y maestría en dirección de mercados, actualmente candidata a PhD en Diseño de la Universidad de Palermo, Buenos Aires, Argentina.

\title{
Introducción
}

En este artículo se analiza el carácter tanto discursivo como metafórico del vestido en la publicidad de moda.

La narración del vestido es un elemento constante: cuenta perspectivas históricas, culturales y sociales de quien lo porta y en esta medida, se ha construido como un elemento del lenguaje, el cual puede ser leído, traducido e interpretado como un "texto cultural" en términos del semiólogo Yuri Lotman (Lotman \& Semiosfera, 1998). 
El carácter semiótico y discursivo del vestido queda contenido y representado en la fotografía publicitaria de la moda de la época en que se produce. En este artículo, que aborda la década de 1990 en Colombia, se muestra cómo este discurso se conformó a partir de la construcción de una erotización que puede ser leída e interpretadas en la publicidad. A partir de este análisis semiótico-discursivo que parte de lo objetivo y concreto de las fotografías y publicidades de la época, se encontró una continuidad de arquetipo publicitario que propone una imagen altamente erotizada de la mujer en la moda, y que la muestra con una corporalidad esbelta y artificial que se construye como la "hexis corporal" o el equivalente al "hábitus" (Bourdieu, 2000), es decir de un uso social del cuerpo de la mujer en la cultura que la construye en paradigma de mujer para la época.

A esta hexis se llega como una forma no sólo corporal sino como un modo de comportamiento, convirtiéndose en un signo de la identidad social de la esfera cultural en la que se inserta, y que coincide aquí con el periodo de conflicto narco en Colombia.

Es importante resaltar las fotografías como escenarios de imagen y representación de una tipología de mujer, por ende resulta no menos importante entender el carácter de dispositivo de la imagen fotográfica, en el sentido que le da Agamben (2011).

De esta forma, a la luz de un análisis semiótico y discursivo, se presenta un hilo argumentativo sobre la relación entre el vestido, el cuerpo y el contexto del conflicto narco de la década de 1990 en Colombia: De esta relación entre los sujetos, los objetos culturales y la cultura surge una subjetividad de mujer altamente erotizada.

Este proceso de lectura e interpretación del sentido de la moda, permitió identificar conceptos culturales sobre la mujer a través de la imagen. Y posibilitó comprender ese carácter hablante del vestido y cómo sus imágenes asociadas revelaron tensiones o influencias subyacentes que generaron sujeción.

\section{Lo "narco" como marco de referencia de la década de 1990}

La década de los años 1990 fue para Colombia una de las más violentas de su historia reciente. En este tiempo el tráfico de drogas fue el negocio ilegal más lucrativo, e involucró a muchas personas urbanas y rurales en sus cadenas de producción.

Si bien el origen de este fenómeno se puede rastrear desde los años sesenta y setenta, con la conformación y extensión de cultivos ilícitos, la posterior emergencia y consolidación de los carteles de la droga hizo que hacia 1980 se acrecentara la organización del narcotráfico en Colombia (León et al., 2008).

La organización narco se construyó principalmente por carteles compuestos jerárquicamente por capos, los grandes agentes mafiosos del narcotráfico, por traficantes, vendedores, productores, y también por sicarios o asesinos a sueldo (Corcione, 2018).

Fueron los carteles del narcotráfico los protagonistas de las noticias colombianas más resonantes de la época. Junto con los actos violentos que se originaban en la guerra directa contra el estado colombiano que se instauró en ese entonces, resonaban también por sus excentricidades, riqueza y lujos, expresados en una estética y un gusto particular. Según 
Corcione: "Uno de los rasgos más distintivos del fenómeno, después de la violencia, es el gusto" (2018, p. 3).

$\mathrm{Al}$ abrirse al país, en esa extensión paulatina del sentido del gusto y de la estética de los capos era evidente la existencia de una "narco-estética" y de una "narco- cultura". En palabras del semiólogo Omar Rincón:

La narco cultura se produce, expresa en tierras, armas, autos, mujeres y trago como símbolos de éxito popular y entretenimiento; viviendas y vestuarios como realización de los sueños; las músicas de celebración de la marginalidad y de los heroísmos precarias de la paralegalidad; religiosidad como ámbito mágico del destino; telenovelas como discurso público de contestación; cine y literatura que seducidos por la riqueza estética y ética de esta forma cultural, llegan a celebrarla como prácticas de lo popular $(2013$, p. 6).

Para 1990, lo "narco" se tomó las pantallas de la televisión con telenovelas que buscaban mostrar historias cercanas a la realidad. Crónicas, biografías y diferentes expresiones de lo narco empezaron a rodar por los medios de manera constante.

Todo lo narco se mostró con el mensaje del poder del dinero y de la violencia con crueldad. Por medio de estos dos protagonistas se generaron diferentes mensajes e imágenes que mostraban a los narcos como personajes muy ricos, rodeados de mujeres, modelos, autos, oro, brillo, lujo, excentricidad y códigos de violencia justiciera. Lo narco se convirtió en todo un espectáculo, en el sentido que la da Guy Debord, y que poco a poco se fue generando una moda de ese estilo y gusto en la cultura colombiana.

\section{Del lenguaje de la cultura, la metáfora y la mujer}

El abordaje teórico de la cultura se ha hecho desde la teoría de la "semiosfera" de Yuri Lotman (1990), quien presenta el concepto de semiosfera cultural como ese espacio y tiempo definido que funciona como un organismo dinámico y sistémico, con agentes o actores que modelizan. En la estructura de la semiosfera existe un dialogo y lenguaje que se manifiestan en diferentes expresiones como símbolos y códigos que la conforman. En palabras de Lotman, "la semiosfera se caracteriza por una serie de rasgos distintivos" (1996, p. 12). En este sentido, son las diferentes expresiones las que la construyen como lenguaje. Y por ende, en cultura o semiosfera, y ésta es productora de textos definidos en diferentes niveles. Es esta estructura, una esfera cultural dialoga con otras, y a su vez está inmersa en una más grande. En sus fronteras, la semiosfera entra en contacto con otras esferas culturales o semiosferas, y es allí donde ocurren espacios de diálogo, interacción y traducción. En este sentido lo narco, entendido como una semiosfera, la narcosfera, produjo diferentes textos, representados e identificables como parte su cultura.

En esta narcosfera se da el espacio de diálogo y de construcción de diferentes subjetividades en el que la "mujer" se construye, como indicó Simone de Beauvoir: 
Cómo hace la mujer el aprendizaje de su condición, como la experimenta, en que universo se encuentra encerrada [...] Cuando empleo la palabra 'mujer' o 'femenino' no me refiero, evidentemente, a ningún arquetipo a ninguna esencia inmutable; detrás de la mayoría de mis afirmaciones es preciso sobreentender 'en el estado actual de la educación y las costumbres' (2019, p. 205).

De esta forma, la subjetividad de las publicidades de la mujer en la semiosfera narco tendrá de necesidad unas correspondencias culturales con las fuerzas que la han construido. Como siguiente abordaje para conceptualizar e interpretar esta investigación se tomó el concepto de metáfora como una operación del lenguaje y la conceptualización: "la esencia de la metáfora es entender y experimentar un tipo de cosa en términos de otra" (Lakoff \& Johnson, 1998, p. 41) En nuestro caso, son sobre todo las imágenes, fotografías y representaciones de la época metáforas de la vida cotidiana.

Este carácter narrativo y hablante de las imágenes también se incorpora en el vestir y la moda. "No existe nadie como conciencia de sí mismo si no es en relación con una colectividad y a través de ella" (Squicciarino, 2012, p. 17). De esta forma, y en diálogo con el texto de la cultura expuesto por Lotman (1990), existe una correspondencia entre la cultura, sus manifestaciones y sus discursividades.

Las fotografías de moda y las publicidades son importantes espacios de representación de la cultura, y también escenarios para la representación y presentación de lenguajes, conceptos e ideologías de su contexto.

Para la filósofa y activista Judith Butler, la fotografía cumple un papel muy importante en tanto retrata, representa, referencia y aclara:

La fotografía no solo retrata, sino que también construye y aumenta el acontecimiento -si puede decirse que la fotografía reitera y continúa el acontecimiento- estrictamente hablando, sino que se torna crucial para su producción, su legibilidad, su ilegibilidad y su estatus mismo como realidad (2018, p. 117).

Teniendo en cuenta el papel de la fotografía en las revistas y publicidades es fundamental decir que aquella reitera y comunica mediante la crónica o imagen visual, y que estas comunicaciones se corresponden con los fines publicitarios de la moda.

En este sentido resulta valioso entender el papel de la publicidad "La publicidad vende realidades personificadas que se convierten en protagonistas del relato" (Guasch, 2004, p. 51), y en esta perspectiva dialoga con las realidades contextuales para tener afinidad, asociación y afiliación. Como lo indica Sánchez:

La publicidad es un producto cultural, pues, es a partir del estudio e identificación de sistemas de significación propios de la cultura -en la que se encuentran los grupos sociales a quienes va dirigida su acción- como el publicista logra imprimir fuerza significativa a su estrategia comunicativa. Pero también la publicidad es generadora de cultura ya que su proceso genera nuevas significaciones... (2008, p. 380). 
Entre esas representaciones que son objeto de significación está por supuesto la de la mujer, categoría de análisis que ha sido estudiada bajo diferentes enfoques. La comunicación de su corporalidad es clave en el presente análisis como parte de un aprendizaje y representación cultural; por lo que es importante tomar el concepto de hexis corporal: "[...] -equivalente del habitus latino- se refiere a la teoría mas general de ese habitus. Designa la manifestación corporal e incorporada por el habitus" (Détrez, 2017, p.117).

Con este conjunto de conceptos se hace un abordaje interpretativo frente a la construcción social de la mujer en la publicidad de la década de 1990 en Colombia.

\section{Métodología y corpus}

Teniendo en cuenta el enfoque conceptual de este trabajo, se planteó una metodología de investigación cualitativa e interpretativa con el objetivo de comprender los cánones de belleza de la mujer presentados y representados en medios de circulación nacional como las revistas Carrusel y Cromos, y diarios como El Espectador y El Tiempo, en la década de 1990 en Colombia.

Para la interpretación y análisis de las imágenes publicitarias fue fundamental entender el papel de las revistas y los diarios como fuente de análisis documental e histórico. En el caso de Carrusel y Cromos, por su enfoque directo al público de mujeres del país, aparte algunas noticias de interés general, había páginas relacionadas con la moda, la farándula, recetas, dietas y sexo, secciones que permitieron hipotetizar la ubicación y rol sugerido para la mujer para la vida social y familiar, con un énfasis en la belleza y la moda.

La revisión de estos medios y revistas permitió recopilar un corpus de cerca de 160 fotografías y publicidades de moda, sobre las cuales se desarrolló un análisis visual discursivo y semiótico.

El método de interpretación semiótica visual que se siguió en la investigación estuvo inspirado en el de Jean-Marie Floch, y que éste utilizó para describir el "Total look de Coco Chanel” (Floch, 1967). En él se entiende el look como un complejo de signos sujetos de interpretación y correspondientes: "se trata de un conjunto cerrado, de un todo, sensible e inteligible a la vez" (Floch, 1967, p.187).

Es importante destacar que la revista Cromos, principal medio que registró las fotografías y publicidades de la década, es la revista más antigua de Latinoamérica. Fue fundada en 1916 en Bogotá y mantuvo una línea editorial que combinaba secciones de literatura, política nacional, artes y sociedad, con publicaciones semanales de circulación nacional que se caracterizaron por llegar a las capitales el todo el país y que capturaron al público general pero especialmente al femenino por su especialidad en la sección de moda, belleza y sociedad dirigida a mujeres.

La revista Carrusel, más reciente, tiene 44 años, y se ha enfocado en un público femenino con secciones sociales, de belleza, estética, bienestar y moda.

Como textos fuente que registraron modelos y conceptos de mujer que se presentaron en Colombia en la década, comunicando roles y modelos emergentes de mujeres, su análisis es ineludible. 
Así mismo, para la revisión de las fotografías y publicidades de la década, se consideraron 10 fotografías por mes de las publicidades de moda y páginas sociales de los diarios arriba mencionados para cada año de la década. Algunas de estas coincidieron en circular en varios medios al mismo tiempo.

\section{La belleza y su imagen de mujer}

El análisis de la construcción de la belleza y sus ideales es una manera de entender la formación de presiones sociales culturales y políticas sobre la mujer, que moldean y excluyen subjetividades que no se amoldan a las reglas o a los estereotipos que se desprenden de dicha construcción.

Para los años 1990 las publicaciones de publicidades de moda y las fotografías de páginas sociales mostraron una transición en la forma de belleza y paradigma de la mujer colombiana, junto con su indumentaria, enunciando para ella diferentes roles que juntos conformaban un nuevo "mito" alrededor de la belleza. Nos referimos a este mito en los términos de Naomi Wolf:

El mito de la belleza se basa en esto: la cualidad llamada belleza, tiene existencia universal y objetiva. Las mujeres deben aspirar a personificarla y los hombres deben aspirar a poseer mujeres que la personifiquen. Es un imperativo para las mujeres, pero no para los hombres, y es necesaria y natural, por qué es biológi$\mathrm{ca}$, sexual y evolutiva. Los hombres fuertes luchan por poseer mujeres bellas, y las mujeres bellas tienen mayor éxito reproductivo que las otras (Wolf, 1991):

Precisamente este mito se convirtió en una norma y reflejo de la sociedad dentro de la semiosfera narco.

El comienzo de la década de 1990 presentó a una mujer con diferentes influencias o matices, con especial énfasis en los años ochenta en los que en Colombia se mezclaron culturalmente el auge del rock en español, la rebeldía y la indumentaria con su discurso unisex. Como consecuencia de esta influencia había una disminución de la feminización o masculinización de la indumentaria en la moda (Figura 1).

Para este entonces fue el blue jean o vaquero una prenda para hombres y mujeres, democratizada y sin influencia sobre los géneros. Las publicidades de la época se sumaban al discurso de la moda sobre la libertad, la juventud, la rebeldía y la informalidad, rasgos característicos de los ochentas y cuyos ecos aún resonaban a comienzos de los años noventa. Pasando revista al look total en las publicidades y fotografías se puede evidenciar que las mujeres allí retratadas mostraban una indumentaria, peinado y accesorios menos conservadores que sus antecesoras, bajo la influencia, como se dijo anteriormente, del rock y del vaquero como símbolo de rebeldía e igualdad entre los sexos, y con la apariencia de un rol desinhibido. 


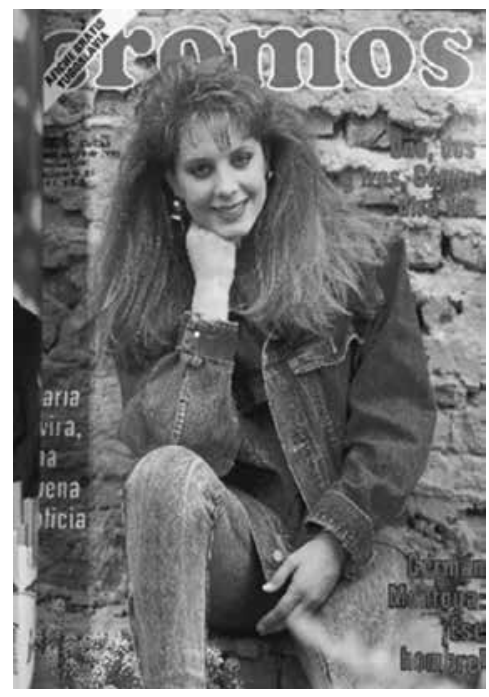

Figura 1. Mujer informal. Fuente: Portada revista Cromos. ED. 3767/68bog, 9 de Abril de 1990.

En la mayoría de las publicidades de esta primera época el plano principal se enfocaba en mostrar el rostro, con un primer plano enfocado en la mirada, directo hacia los ojos, en escenas caracterizadas por la intensidad y la fuerza a comunicar. En esta perspectiva la fotografía tenía un plano completo que reunía el conjunto como un todo significante. El cuerpo y la indumentaria mostraban un discurso visual que enunciaba mujeres activas con una actitud de autonomía, independencia y exploración.

Llegando a la mitad de los años 1990, el cabello corto continuó su protagonismo, y también los jeans como prenda principal, los cuales tenían una silueta suelta, pero empezando su talle en la cintura. Se puede decir que era el jean que venía de la línea masculina, sin mayores cambios, hecho que marcó los años 80 y continuó hasta 1990. Esta indumentaria de moda hace recordar la silueta creada por Channel, esa que no estaba construida desde lo femenino en palabras de Floch: "Chanel 'montó' su look a partir de signos ajenos al mundo de la moda femenina de la época” (1967, p. 182).

Siguiendo el avance sobre esta década, se dio una tendencia al uso de blusas ombligueras, las que dejaban al descubierto el ombligo, y con ellas el énfasis se puso en una búsqueda cada vez más evidente de la delgadez. Así, prendas como el top se ciñeron alrededor de la silueta corporal delgada que se presentaba como la belleza del momento, y con esta, una relación detectada como causa efecto entre el cuerpo y la indumentaria.

Pero para el comienzo de la década de 1990, el conflicto narco y la violencia empezaron a figurar como principales noticias en el país. Y fue así como empezaron a resonar las excentricidades, el derroche, los grandes volúmenes y el sentido del gusto narco en el país. Esta relación entre el gusto y lo narco empezó a agudizarse con el auge de los carteles, de esta manera su estilo empezó a establecerse como cultura. 
Entendido el sentido del gusto y la voluptuosa estética narco como un espectáculo, se reflejaba en éste un poder que podía comprar o modificar cualquier cosa. Esta tendencia, convertida en corto tiempo en flagelo, fue una presión muy fuerte para la sociedad colombiana, que se vio presa entre la violencia de los nuevos códigos y textos de la narcosfera y el espectáculo del derroche.

Para ese entonces puede verse cómo la publicidad de la moda empezó su transformación del paradigma de belleza de mujer, produciendo una ruptura con respecto al look anterior, el cual mostraba a una mujer independiente, liberada, lo que era reforzado por el "look total” (Floch, 1967) como complejo sígnico, y de ahí la indumentaria con características de informalidad y aventura.

En la era del conflicto narco la voluptuosidad empezó a ganar protagonismo. La hexis corporal se modificó y la mujer presentada en la publicidad, sumada a las temáticas de las secciones de las revistas, mostraba como principal interés la salud y la belleza; las dietas para lograr la corporalidad anunciada eran también una parte importante y protagónica. Hacia 1995 la figura de la mujer empezó a recibir énfasis en partes de su cuerpo como busto y el derrière. Tanto la indumentaria como el cuerpo empezaron a experimentar mayores transformaciones. Para ese momento las revistas, la publicidad y las páginas sociales empezaron a mostrar o descubrir cada vez más el cuerpo de la mujer. El busto realzado y voluptuoso era una parte protagónica para la construcción de la belleza femenina; las camisas empezaron a desabotonarse, generando un escote cada vez más profundo; y empezó a mostrarse con frecuencia el busto artificial o de silicona, coincidente con el auge de la cirugía plástica en Colombia.

Con esta influencia, la voluptuosidad de las mujeres vistas a través de su busto y derrière hizo de estas partes puntos focales permanentes de la publicidad de moda, y con ellos empezó la construcción de un discurso visual de la mujer erotizada y presa de la belleza. Tal como nos lo recuerda J. Butler, "la fotografía retrata, tiene una función representacional y referencial” (2018, p. 124), de manera que la imagen referencia y presenta la corporalidad y belleza de la época.

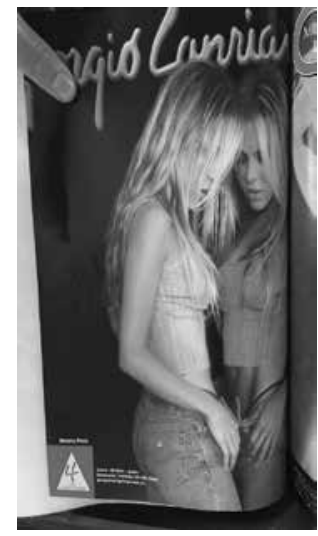

Figura 2. Mujer erotizada. Fuente: Revista Cromos, ED. 4203 -bog, 18 de octubre de 1999 p. 48. 


\section{El discurso visual de la moda en 1990}

Como en una obra de teatro y los performances de los actores, las fotografías y publicidades presentaron un tipo de mujeres sobre las que se quiso existiera una lectura bien definida de deseo y erotización de su cuerpo. El cuerpo, a su vez, quedó marcado por esta representación. Siguiendo a Colaizzi: "En la visión de este espectáculo, el sujeto inscribe su cuerpo, su deseo de comprensión y, a su vez, queda marcado por él” (2007, p. 31).

Esta visión sobre la importancia de la representación enmarca a la publicidad y la fotografía como importantes escenarios de historización de la mujer, en los cuales se han registrado las marcas y discursos imperantes sobre el género, lo que implica una visión de la imagen no sólo para entender las tendencias de la moda, sino también el contexto cultural y socio-histórico que la contiene.

En esta instancia es posible identificar la importante tensión que subyace a la construcción de las publicidades y fotografías. Si bien pareciera solo un paso más por las tendencias y transformaciones de la moda, esta ruptura y cambio de las formas de la indumentaria en los años de 1990 muestra cómo se transformaron los valores de la belleza de la mujer colombiana, coercionados por los valores culturales y sociales que se vinculan directamente con el conflicto narco y su cultura.

Vista la cultura narco como una "semiosfera" (Lotman, 1998), fuente emisora y productora constante de textos en la cultura que reflejaron su poder, resulta claro que también ella generó una fuerte presión e influencia que comunicó mediante múltiples formas su sentido del gusto, y con él un discurso y una mirada sobre las mujeres.

No fue casual que a mediados de la década de los noventa en Colombia se produjera un auge de la cirugía plástica (Taussig, 2014), en la que las mujeres solicitaban aumento de senos, reducción de cintura y aumento de glúteos. La belleza construida en el quirófano empezó a exhibirse en conocidas modelos, y con el tiempo fueron muchas novias y acompañantes de los narcos fueron las principales clientes, consolidando la relación entre el cuerpo voluptuoso y el exceso narco, haciendo más y más evidente el fenómeno de la narco estética en Colombia (Andrade Salazar, Peña, Giraldo, 2017).

Esta estética corporal trasformada y construída quirúrgicamente se convirtió en paradigma de belleza, en la hexis corporal de la narcoestética que se presentaba como la mujer de éxito del momento. Así llegó a las portadas de las revistas, a las pasarelas de moda y a las publicidades como la mostrada en la Imagen 1. En este sentido la indumentaria y el cuerpo empezaron una relación de ida y vuelta, donde el cuerpo modificado se quería exhibir más y la indumentaria lo complementaba, construyendo una subjetividad marcada por el deseo y la erotización.

Estas marcas de género que de la publicidad y los medios se reforzó mediante narco-novelas, espacios de presentación y representación que construyeron una subjetividad marcada por la voluptuosidad y erotización de la mujer, a la que además la mostraban complaciente con el género masculino.

La década de los años 1990 en Colombia fue entonces en la que las imágenes de la mujer en las revistas, páginas sociales y publicidades fueron feminizadas utilizando discursos visuales y metáforas biologizantes en las que se construía una belleza y un modo de mujer 
erotizada. Todo ello confluyó en la ritualización y mitificación del cuerpo para conseguir la corporalidad de éxito.

Y fueron las escenas de la publicidad y su discurso visual un constante dispositivo que formó y apoyó la construcción de esta subjetividad en la narcosfera.

\section{Conclusión}

Este trabajo permitió rastrear la representación de la belleza de la mujer en la década de 1990 en Colombia, en la cual se evidenció una marcada ruptura frente a la forma y discurso de la belleza de los años 1980.

La fotografía, la publicidad, los diarios y las revistas de la época fueron una fuente de historicidad que evidenciaron la representación de los paradigmas de belleza y los roles de mujer en ellos enunciados, siendo esta representación el reflejo de la cultura y sociedad del momento, dominada por el conflicto y la estética narco.

La transformación de la imagen y la belleza de la mujer pasó de estar influenciada por un discurso visual unisex, liberador y rebelde, que venía de la onda mundial del rock de la década de los años 1980, a estar bajo la influencia de lo narco en la década de 1990: Los signos principales de esta transformación modificaron la cultura mostrando matices de erotización sobre las mujeres.

Este discurso erotizador se reflejó en múltiples medios. En ellos la voluptuosidad construida mediante cirugías era un factor común. Y con esta nueva corporalidad las mujeres modelos acompañantes de los narcos y que adquirieron fama por ello también se unieron a dicha estética corporal o narco estética. Y fue así como creció la presentación y representación del paradigma de belleza como protagonista en espacios sociales y de farándula, en videos y narco novelas.

En este sentido, el discurso visual de la belleza narco y el de las publicidades en revistas empezó a mezclarse formando una hexis corporal narcotizada que fue construida, presentada y reafirmada por los medios de comunicación como una panorámica del contexto de la sociedad de la década, mostrando otra mujer real, otro tipo de subjetividad, con un rol emergente y popular en el país.

La mujer así presentada resultó ser un sujeto efecto de los valores sociales y culturales. Presa de un nuevo concepto de belleza en la narcosfera, bajo los signos de la erotización y del deseo, es preciso señalar que estas características resultaron ser fuertes normas sobre la construcción de la mujer y su rol, haciendo que en esta década del conflicto narco se marcara un revés para la equidad del género femenino ganado en décadas anteriores en las que prendas como el jean había sido abanderadas, y llevándola a una posición para la complacencia de lo masculino a través de la erotización de su cuerpo y de la modificación su indumentaria, de lo cual queda el registro en las fotografías publicitarias de la década. 


\section{Bibliografía}

Agamben, G. (2011). ¿Qué es un dispositivo? Sociológica Mexico, 73, 249-264. Retrieved.

Andrade Salazar, J. A.; Peña, B. D. y Giraldo, M. (2017). Narcoestética en Colombia: entre la vanidad y el delito. Una aproximación compleja. Drugs and Addictive Behavior, 2, 38-66.

Beauvoir, de S. (2019). El segundo sexo. (P. R. House, Ed.). Bogotá.

Bourdieu, P. (2000). LA dominación Masculina. (Anagrama, Ed.). Barcelona.

Butler, J. (2018). Marcos de guerra (2nd ed.). Bogotá: Paidós, Ed.

Colaizzi, G. (2007). La pasión del significante, teoría de género y cultura visual. Madrid: B. Nueva, Ed.

Corcione Nieto, J. S. (2018). Narcoestética: El gusto narco en Colombia en la década de los años ochenta y noventa. Autor: Universidad de Bogotá Jorge Tadeo Lozano. Retrieved from https://expeditiorepositorio.utadeo.edu.co/bitstream/handle/20.500.12010/3141/ Tesis.pdf? sequence $=1$ \&isAllowed $=\mathrm{y}$

Détrez, C. (2017). La construcción social del cuerpo. Bogotá: Universidad Nacional de Colombia., Ed.

Floch, J. (1967). total look, (1949), 181-200.

Guasch, A. M. (2004). Los “cuerpos" del arte de la posmodernidad. In CendeaC (Ed.), Cartografías del cuerpo; La dimensión corporal en el arte contemporáneo. Murcia.

Lakoff, G. y Johnson, M. (1998). Metáforas de la vida cotidiana. Barcelona: Cátedra, Ed.

León, A. Cruz, A. \& Rojas Rivera, D. M. (2008). El narcotráfico en Colombia. Pioneros y capos. Dialnet.

Lotman, I. M. (1996). La semiosfera. Madrid.

Lotman, I. M. (1998). La semiosfera I.

Lotman, I. M. (1998). La semiosfera I.I.S.B.N. Retrieved from https://circulosemiotico.files. wordpress.com/2012/10/i-lotman-semiosfera-ii.pdf

Rincón, O. (2013). Todos llevamos un narco adentro - un ensayo sobre la narco / cultura / telenovela como modo de entrada a la modernidad. Matrizes, 7 (December), 1-33.

Sánchez, V. (2008). Semiosis y Publicidad. In Universidad de Bogotá Jorge Tadeo Lozano (Ed.), Ensayos semióticos (pp. 375-411). Bogotá.

Squicciarino, N. (2012). El Vestido habla, Consideraciones psicosociológicas sobre la indumentaria. (S. e imagen CATEDRA, Ed.). Madrid.

Taussig, M. (2014). Belleza y Violencia, Una relación aún por entender. (U. del Cauca, Ed.). Popayán.

Wolf, N. (1991). El Mito de la Belleza. (Emecé, Ed.). Barcelona.

Abstract: This article is an excerpt of the research of the doctoral thesis in design: "The
dress and the conflict in Colombia 1984 to 2000. The case of the Colombian jean". We
present a reflection on the image of woman that was represented in magazines and na-
tional newspapers, based on the review and analysis of both photography and fashion
advertising from the 1990s in Colombia. The visual discourse associated with this woman 
is also analyzed. To achieve this analysis, it was necessary to deepen the relationship of the image with the contexts, the contrast with the previous historical period, and delve into the corporal hexis of clothing to understand its continuities and transformation in order to find a direct relationship with the cultural sphere of the "narco" world, which not only produced violence and illegality in Colombia, but also inserted itself into the culture through texts, objects, modes and objective expressions that produced imaginaries of power that influenced and transformed a part of Colombian society towards a "drugged" society with a narco-aesthetic.

Keywords: semiosphere - woman - narco-aesthetics - dress - Colombia.

Resumo: Este artigo é parte da pesquisa da tese de doutorado em design: "O vestido e o conflito na Colômbia de 1984 a 2000. O caso do jeans colombiano". Apresenta-se aqui uma reflexão sobre a imagem da mulher representada em revistas e jornais nacionais, discutida na revisão e posterior análise da fotografia e da publicidade de moda da década de 1990 na Colômbia, e analisa-se o discurso visual associado às mulheres. Para a análise, foi necessário aprofundar a relação da imagem com os contextos, em contraste com o período histórico anterior, e aprofundar a hexis corporal do vestuário para compreender as suas continuidades e transformações, o que permitiu encontrar uma relação direta com o esfera, cultura do mundo das narco, que não só produziu violência e ilegalidade na Colômbia, mas também se inseriu na cultura por meio de textos, objetos, modos e expressões objetivas que produziram imaginários de poder que influenciaram e transformaram uma parte da sociedade colombiana em direção a um sociedade drogada e produtora de uma narcoestética.

Palavras chave: Semiosfera - mulher - narcoestética - vestido - Colômbia.

[Las traducciones de los abstracts fueron supervisadas por el autor de cada artículo] 